Educational Psychology, Vol. 21, No. 4, 2001

\title{
Negative Social Experiences and Dropping Out of School
}

FRANK VITARO, DENIS LAROCQUE, MICHEL JANOSZ \& RICHARD E. TREMBLAY, Research Unit on Children's Psycho-social Maladjustment, University of Montreal, Montreal (Quebec), Canada

ABSTRACT The purpose of this study was to test a prediction model of early withdrawal from school with a sample of 751 low SES boys with an emphasis on the role of peer-related variables. The model included early disruptiveness and academic performance as the main triggering factors of a chain of events that included social acceptance from peers, and association with deviant/dropout friends. The model also included socio-familial variables, as well as parental variables as covariates and as potential moderators. Results confirmed the power of early disruptiveness and early academic performance to predict dropout. However, the effect of these variables varied according to dropout age. Low social acceptance from classmates made no additional contributions in predicting the process of early school disengagement. However, affiliation with deviant/dropout friends did. No moderating effects for parenting variables were found. Socio-psychological processes involved in the trajectory leading early disruptive boys to drop out of school and the importance of targeting early disruptiveness and academic difficulties to prevent school dropout are stressed in the discussion.

\section{Negative Social Experiences and Dropping out of School}

Dropping out of school before the end of secondary school has become a major problem in North America. Since 1990 in the USA, around 20\% of all youths aged 16-24 years are classified as dropouts, meaning they were not enrolled in school and had not graduated (McMillen et al., 1993). Prevalence rates in the USA, however, vary greatly depending on ethnic origin and SES variables. Dropout rates in Canada during the same period are slightly above the rates in the USA (Statistics Canada, 1995). In Canada, the highest dropout rates, ranging from 25 to $36 \%$ since 1990 (between 32 and $42 \%$ when only boys are considered; Statistics Canada, 1995) are found in Quebec. These rates remain high even after considering that about $10 \%$ of dropouts return to school and manage to get a high school diploma by age 20 . 
Personal and societal consequences of dropping out of school are costly. Dropouts experience higher levels of unemployment and receive lower earnings than high school graduates (Rumberger, 1987). Dropouts are also more likely than graduates to become dependent on welfare, engage in illegal activities, and experience health and affective problems (Rumberger, 1987). Finally, high rates of dropping out of school create a negative momentum for youths in a society, particularly during difficult economic periods when even a high school diploma does not guarantee a job. Such momentum may foster even higher dropout rates in the future.

Most studies that investigated the predictive variables of school dropout focused on personal (i.e. behavioral, academic, intellectual) and familial factor. These studies found that an early disruptive profile (Ensminger \& Slusarcick, 1992), low achievement in elementary school (Garnier et al., 1997), and parental support and supervision (Howell \& Frese, 1982; Rumberger et al., 1990) predict early withdrawal from school even after controlling for socioeconomic factors. However, as underlined by Hymel et al. (1996), far less attention has been given to the role of peers in contributing to school dropout. More than a decade ago, Parker \& Asher (1987) suggested that social factors may be better estimates of leaving school without graduating for the majority of dropouts with average or above intelligence than cognitive or parental factors. The few studies that investigated the role of peers did so without considering academic and familial factors (e.g. Elliott \& Voss, 1974; Cairns et al., 1989), however. Consequently, no study (to our knowledge) has considered the contribution or the role of peer-related variables above and beyond personal and familial variables in a comprehensive model intended to predict early withdrawal from school.

Two peer variables have been linked with dropping out of school: rejection from conventional peers and association with deviant peers. For instance, many children with disruptive behaviors experience peer rejection (Coie, 1990). This is important in that peer rejection has been predictively linked, in some, but not in all studies, to dropping out of school (see Hymel et al., 1996). In addition, many rejected children have no friends in the classroom that might buffer the impact of negative social experiences at the group level. Actually, lack of friends may increase the risk for school disengagement. Kupersmidt et al. (1990) suggested that rejection from peers and lack of friends exacerbated the frustrations of low grades and punishment for low achievement and increased adolescents' motivation to leave school prior to graduation. In support to this position, Kupersmidt (1983) showed that peer status significantly predicted later academic adjustment even after controlling for sex, race, grade point average and child's reputation among peers for starting fights. However, in this study, academic maladjustment included grade retention and truancy and not just dropping out of school. Ollendick et al. (1992) also reported that 9-year-old rejected children failed more grades and were more likely to dropout of school 5 years later than non-rejected children. Consequently, these negative social experiences may contribute to or mediate the link between disruptiveness and dropping out. In addition to their independent or mediating role, peer acceptance may also condition (i.e. moderate) the propensity of disruptive or learning disabled children to dropout of school and help explain why some, but not all at risk children dropout of school.

In turn, peer rejection might be moderated by parental factors. For example, Steinberg et al. (1992), showed that parental support for academic attainment buffered children who were unpopular with their peers from dropping out of school. However, it is also possible that social acceptance has no independent contribution to dropping out of school as indicated by findings from Kupersmidt \& Coie (1990) and 
Cairns et al. (1989). In these studies, peer rejection was merely a social indicator (i.e. a marker) of children's behavioral and academic problems. Indeed, the role of peers in school dropout is far from clear, especially since previous studies did not include personal and familial variables in addition to peer-related factors.

Furthermore, difficult life experiences during primary school might lead to and be further enhanced by associating with deviant/dropout friends during early adolescence. Association with deviant friends might indeed prove necessary (i.e. causal) in the decision process to drop out of school through the modelling effect and the norm setting such behaviours convey or through the involvement in incompatible normbreaking activities that deviant friends foster. To illustrate this part, Elliott \& Voss (1974) assessed the friendship network of 8th through 12th grader children over a 5-year interval. The children were asked to indicate the number of friends who quit school prior to graduation and whether their best friend was still in school or not. The proportion of students in school that the children affiliated with and who would eventually quit school prior to graduation was also assessed. Significant, but moderate correlations between exposure to friends who dropped out of school prior to graduation at the beginning of the study and later dropout status were found. More importantly, gains in exposure to dropout friends (for those who were not initially exposed) were also related to later dropout status. Failure to control for initial behaviour problems or academic difficulties, however, limit the impact of this finding. Cairns et al. (1989) also showed that 7 th graders most vulnerable to dropping out of school tended to affiliate with other students who were also at risk for dropping out. These authors, however, did not test for the role of dropout friends in their overall model linking aggressiveness and low grades to dropping out of school.

Peer rejection at the group level and friendlessness at the dyadic level as well as association with deviant peers may operate in different ways to predict later school dropout (cf. Parker \& Asher, 1987; Kupersmidt et al., 1990; Hymel et al., 1996). First, these variables could mediate the effect of early behaviour problems and school difficulties, as well as socio-familial variables. Secondly, they could moderate the effect of these variables. Thirdly, their role might be spurious through their relationship with personal, academic and socio-familial variables. In other words, once the latter variables are controlled for, peer-related variables could be found to play no role. Finally, they could make independent and additive contributions above and beyond the other variables. Consequently, it is necessary to control for behavioral, academic and sociofamilial factors in order to assess the unique contribution of peer-related variables to the process of dropping out of school.

At a more methodological level, it is important to note that the majority of studies examined variables predictive of school dropout during early or even mid-adolescence (Elliott \& Voss, 1974; Cairns et al., 1989; Kaplan et al., 1997). These studies identified predictors such as school failure, absenteeism, low school motivation or association with deviant peers. However, these predictors are themselves the by-product of earlier problems and thus may be considered intermediate steps between early childhood problems and subsequent school dropout. Furthermore, some studies establish dropout status when the participants are young adults (e.g. Ensminger et al., 1996; Pirog \& Magee, 1997). Their dropout group includes individuals who dropped at different ages, some as early as 15 , while others by age 17 (which corresponds to the normal age of graduation) or even later for those who have been retained behind at earlier grades. This is in contrast with studies that establish dropout status by age 17 (e.g. Cairns et al., 1989) or before (e.g. Rumberger, 1995). In these studies, the dropout group 
includes early dropouts, whereas the non-dropout group includes participants who are close to graduation, as well as participants who are not close to graduation (because they have been retained behind). This methodological difference might account for some of the contradictory results. It also begs the question of whether predictors of early or late dropout are the same or not, and whether the role of peer-related variables is the same with respect to early and late school dropout.

The objectives of this study are two-fold:

(1) to test for the role of peer-related variables (i.e. unpopularity/friendlessness and deviant friends) in a developmental model that integrates personal (i.e. behavioral and academic) and socio-family variables (i.e. demographic factors and parental practices);

(2) to examine whether the role of these variables varies according to the age dropout occurred (i.e. early or late).

It is thus the purpose of the present study to clarify the role of peer-related variables (i.e. unpopularity/friendlessness and association with deviant friends) in the process leading to school drop out while taking into account the personal, academic and socio-familial variables that might also contribute to this process.

\section{Methods}

Sample

Seven-hundred-fifty-one boys participated in this study. They were part of an ongoing longitudinal study started in 1984 with 1034 French-speaking kindergarten children. These boys comprised a community sample representing $87 \%$ of all boys in 53 schools located in disadvantaged areas of Montreal, Canada. All the boys were Caucasians and their parents did not go beyond grade 14 for their education ( $M=$ of 10.5 years of schooling). Parents (principally mothers) provided information about the occupation(s) of parent(s) with whom the child was living. The Blishen et al. (1987) scale for occupational prestige in Canada was used to score each parent's occupation on a continuous scale. This score is based on the average income and average education level associated with occupations in Canada. For boys living with two working parents, the highest parental occupation score was used. The minimum score on the scale (i.e. 17.8) was attributed to boys living in families on social welfare or on unemployment insurance. Thirteen percent of the boys lived in such families. The average occupational prestige score for the whole sample was $38.87(\mathrm{SD}=14.54)$. Comparatively, the average occupational prestige score of a representative sample of parents with same age boys living in the province of Quebec, during the same period, was 42.08, $\mathrm{SD}=12.09$.

The boys were followed annually from age 6 (end of kindergarten) through age 17 which corresponds to the normal time for graduation from secondary school in Quebec. Participants lost through attrition were more disruptive at age 6 and came from more disadvantaged families than the 751 who remained in the sample.

\section{Measures at Ages $6 / 7$ and 10}

All the measures in this section were used to assess the participants both at age 6 (or 7 for academic performance) and age 10. For all variables an average score was 
computed. We thought this would reflect the children's behavioral and academic profile as well as their socio-family situation better than a single data point.

Socio-familial adversity index. Mothers reported:

- family structure (i.e. two-parent, single, blended);

- education levels of both parents or the parent with whom the child was living;

- occupations of both parents or the parent with whom the child was living;

- parents' ages or mother's age at the birth of her first child.

These variables have repeatedly been shown to be related to children's behavioural problems (Robins, 1978; Huesmann et al., 1984; Velez et al., 1989).

For each year, a socio-familial adversity index was constructed by averaging the 0 or 1 scores given to each of the preceding seven variables. Family structure was scored 0 if the child was living with both natural parents. All other cases were scored 1. The other variables were scored 1 or 0 depending on whether the scores for each were in the bottom quartile or not. As already mentioned, the Blishen et al. (1987) scale for occupational prestige provided continuous scale scores for parents' occupations.

In some cases, information about one parent's occupation and/or education level was not available. In those cases, an average adversity index was computed on the available variables (i.e. family structure, one parent's occupation, one parent's education level and age at birth of first child). Thus, four or more variables were required in order for the adversity index to the computed.

About half $(49.5 \%)$ of the children in the sample obtained adversity index scores between 0 and 0.20 (low level adversity). More than one-third (38.2\%) obtained an average adversity index between 0.25 and 0.57 (medium level adversity). Finally, $12.3 \%$ of the children obtained adversity index scores of 0.60 and over (high level adversity).

Disruptiveness. Teachers rated boys' behaviour using the Social Behaviour Questionnaire (SBQ; Tremblay et al., 1991) at the end of the school year. The SBQ is a 32-item behavior rating questionnaire used to assess disruptiveness (i.e. hyperactivityaggressiveness-opposition; 13 items), inattention (four items), anxiety-withdrawal (five items), and prosocial behavior (10 items). Teachers indicated whether items: did not apply (none), applied sometimes (one), or applied often (two). At ages 6 and 10, internal consistency was high for the disruptiveness, inattentiveness and prosociality scales at all ages (alphas $>0.85$ ) and moderate for the anxiety-withdrawal scale (alphas $>0.75$ ). Only the disruptiveness scale was used in the present study. The items comprising this scale were: restless, squirmy, destroys, fights, not liked, irritable, disobedient, tells lies, bullies, doesn't share, blames others, inconsiderate, and kicks, bites and hits.

Academic performance. Performance in French (reading, writing) and in mathematics was collected through the use of children's report cards. Scores in French and mathematics were averaged. This averaged score correlated 0.49 with a measure of verbal IQ (Lorge \& Thorndike, 1950; Veroff et al., 1971) administered at age 13 to the whole sample and 0.61 with the WISC-R at age 9 for a subsample of 150 children. 


\section{Measures at Ages 11 and 12}

The following measures cover a 2-year period (i.e. ages 11 and 12). An average score across these 2 years was computed to provide a more representative profile of the participants.

Negative social experiences. The Pupil Evaluation Inventory (PEI; Pekarik et al., 1976) was used to collect assessments of the participants from their classmates. The PEI contains 34 short behaviour descriptions grouped into three scales:

- aggressiveness-disturbance (20 items);

- social-withdrawal (nine items);

- likeability (five items).

Three items from the likebility scale were specifically used to capture subjects' social experiences in the classroom with respect to unpopularity and friendlessness. These three items were:

- 'Those who are liked by everyone';

- 'Those who are your best friends';

- 'Those who have very few friends'.

The number of nominations subjects received on each item were first standardized within the classroom. Next, the first two items were summed, whereas the third one was substracted. This resulted in a composite score of positive social experience that included a popularity dimension at the group level and a friendship dimension at the dyadic level. Consequently, negative scores (which are scores below the mean) reflect unpopularity and friendlessness.

Participants' classmates (boys and girls) nominated up to four boys in the classroom who best fit each descriptor. A code number was assigned to each boy in the classroom and these were presented in a roster format to the children. Children wrote down the code numbers of four boys whom they felt best fit the descriptor. PEI assessment took place near the end of each school year.

Parental support and supervision. Boys reported on their parents' support (seven items) and supervision (two items). The support items were:

- 'Do your parents congratulate you for things you have done?'

- 'Do your parents complain if you don't have good grades?'

- 'Do your parents explain to you the reasons for some decisions they make with regard to you?'

- 'Do your tell your parents what you would like to become when you grow older?'

- 'Do your parents acknowledge your personal feelings?'

- 'Do you speak to your parents about your feelings and personal thoughts?'

- 'When your parents ask you to do something you don't like, do they first give you some explanation?'

(Average alpha across ages 11 and $12=0.76$.) The two supervision items were:

- Do your parents know where you are when you go out?

- Do your parents know who you hang around with?

(Average alpha across ages 11 and $12=0.74$.) 
Parental measures were included for control purposes and because they might moderate the effect of difficult social experiences (i.e. unpopularity/friendlessness) as suggested by findings by Steinberg et al. (1992).

\section{Measure at Ages 13 and 14}

The following measures were used to assess the participants at ages 13 and 14 years. For purposes of analyses, the responses were averaged over the two assessment periods.

Friends' deviancy. Participants reported about their exposure to deviant-dropout friends over the past 12 months by answering the following three questions:

- How many of your best friends have been arrested by the police for an illegal act they had committed?

- How many of your best friends are members of a gang which commits illegal acts?

- How much does your best friend consider leaving school?

For the first two questions, subjects answered: none (1), a few (2), many (3) or all of them (4). Answers to the third item were coded 1 (not at all), 2 (little), 3 (quite a lot) and 4 (very much). Consequently, for each subject we were able to assess the degree of exposure to deviant-dropout friends, with scores ranging from 3 to 12. Internal consistency of this Exposure-to-Deviant-Friends scale was 0.62 at age 13 and 0.69 at age 14 .

\section{Measure at Ages 15, 16 and 17}

Dropping out of school. Our definition of school dropout follows Pallas and Verdugo's typology: a dropout is an individual who stops attending school before high school graduation, whether or not he or she reenters at a later time. Most researchers endorse this definition (Cairns et al., 1989; Rumberger, 1995; Ensminger et al., 1996).

School dropout status was determined from the computerized lists of the Montreal schoolboard and the Ministry of Education and the subjects themselves. If a subject was not on the annual Schoolboard list, we asked the Ministry of Education to indicate whether he was enrolled in another schoolboard within the province. Because the subjects were French speaking, it is unlikely that many dropouts could, in fact, have transferred to a new school within another province. We also obtained direct confirmation from subjects that they had left school during our annual data collection period. Very few subjects from the final sample dropped out before age 15. However, we might have missed those who were not part of the final sample, as these individuals were more disruptive and socio-economically disadvantaged.

\section{Results}

The inter-correlation matrix between predictors is presented in Table I for the sample of 751 participants (134 dropouts; 617 non-dropouts). Each correlation is significantly different from 0 except the two marked with an asterisk. Table II presents the means and standard deviations for the predictors separately for dropouts and nondropouts. As can be seen, they differed on all the variables except parental support. 


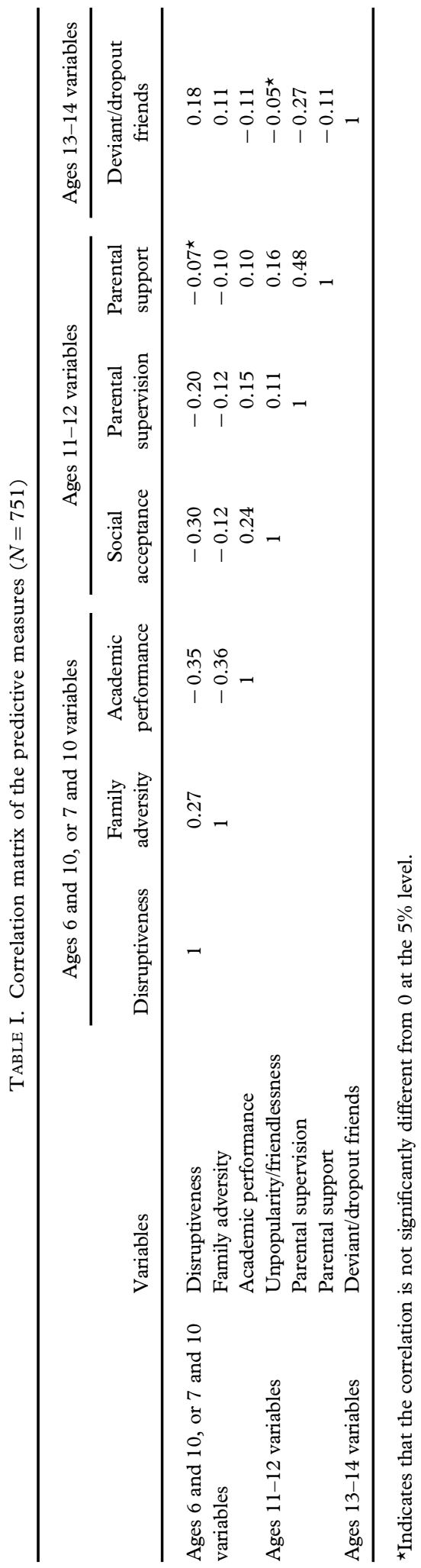


TABLE II. Means and standard deviations (between parentheses) for predictive measures depending on dropout status and $P$-value of the corresponding $t$-tests

\begin{tabular}{llcc}
\hline & \multicolumn{2}{c}{ Status } & \\
\cline { 2 - 3 } & $\begin{array}{c}\text { Non-dropout } \\
(N=617)\end{array}$ & $\begin{array}{c}\text { Dropout } \\
(N=134)\end{array}$ & $\begin{array}{c}P \text {-value of } \\
\text { the } t \text {-test }\end{array}$ \\
Variables & & & \\
\hline Ages 6-10 variables & $2.43(2.20)$ & $3.52(2.22)$ & $<0.0001$ \\
$\quad$ Disruptiveness & $2.90(2.20)$ & $4.74(2.15)$ & $<0.0001$ \\
$\quad$ Family adversity & $7.47(1.08)$ & $6.56(1.16)$ & $<0.0001$ \\
$\quad$ Academic performance & & & \\
Ages 11-12 variables & $5.26(2.21)$ & $4.73(2.35)$ & 0.017 \\
$\quad$ Unpopularity/friendlessness & $7.75(1.83)$ & $7.09(2.14)$ & 0.001 \\
$\quad$ Parental supervision & $5.99(1.49)$ & $5.78(1.59)$ & 0.167 \\
$\quad$ Parental support & & & \\
Ages 13-14 variables & $1.21(1.91)$ & $2.60(2.68)$ & $<0.0001$ \\
$\quad$ Deviant/dropout friends & &
\end{tabular}

\section{Model Testing}

For dropouts, the ages at which the individuals did not return to school (i.e. 15, 16 or 17) were known. To include this information, a discrete-time survival analysis model (Singer \& Willett, 1993), rather than the standard logistic regression model was used. This refinement allowed testing for the potential time-varying effects some predictors may have had on school dropout status. The analyses were performed with SAS LOGISTIC using the method described by Singer \& Willett (1993).

When the dropout group was broken down by age, 19 students left school at age 15, 46 at age 16, and 69 at age 17, giving a total of 134 dropouts. Although a different intercept was fitted for each age, the time varying-effect of the predictors was tested by combining age 15 and 16 dropouts because of the small number of cases at each age. Nevertheless, we were still able to verify whether predictors had a differential effect on early (age 15 and 16) as opposed to late (age 17) dropout.

First, the contribution of each predictor to the prediction of the outcome was examined separately. In order to facilitate comparison of parameters across predictors, base-10 logarithmic transformations of the predictors were conducted. Each predictor made a significant contribution in predicting dropout status except parental support, thus confirming the results of the $t$-tests. In addition, the analysis revealed the possibility that the effect of age 6-10 disruptiveness could be different for early and late dropping out. Age 6-10 disruptiveness significantly predicted early $(\beta=0.25)$ and late $(\beta=0.12)$ dropout statuses, the effect being twice as large for early dropping out. Conversely, age $7-10$ academic performance predicted more strongly late $(\beta=-0.75)$ than early $(\beta=-0.38)$ dropout status. Finally, deviant/dropout friends better predicted early $(\beta=0.32)$ than late $(\beta=0.15)$ dropout status. As for the other variables, the significant contributions of the remaining variables did not vary depending on the age at which the participants dropped out of school (family adversity: $\beta=0.31$ and 0.32 for early and late dropout, respectively; unpopularity/friendlessness: $\beta=-0.08$ and -0.13 for early and late dropout, respectively; parental supervision: $\beta=-0.16$ and -0.16 both for early and late dropout). 
The final model was built in three steps by entering the predictors in a chronological order. At step one, only age 6-10 and 7-10 variables were entered. Age 11-12 variables were added during the second step. The age 13-14 predictor variables were included during step three. As before, the possible time-varying effect of the predictors was tested at each step by comparing the likelihood of nested models. Also, possible non linear effects of the predictors were examined. Finally, a likelihood approach was used to assess all meaningful interaction terms.

The resulting model at the end of each step, including the estimates and standard errors of the parameters as well as their odds ratios, is described in Table III. Odds ratios indicate the increase in the risk of belonging to the dropout group in relation to a unit change in the predictor.

At step one, both disruptiveness and academic performance had significant timevarying effects on dropout status. Disruptiveness had an adverse effect on early dropout status, but no significant effect on late dropout status. Conversely, poor academic performance predicted late, but not early dropout status. Finally, the negative impact of family adversity was modelled by the use of only one parameter because its effect did not significantly change with time.

At step two, the ages 11-12 predictors of unpopularity/friendlessness, parental supervision, and parental support were entered into the equation. The results of this step indicated that unpopularity/friendlessness and parental support were unrelated to either early or late dropout status. Parental supervision, however, was found to be moderately related to dropout status. Less parental supervision had a slight negative impact. Furthermore, the addition of the age 11-12 predictors did not affect the estimates of the parameters of the age 6 and 10, or 7 and 10 predictors.

Finally, the age 13-14 predictor was added to the equation. The negative impact of deviant/dropout friends was significant and differentally related to early and late dropout status. This predictor variable did not modify the estimates for disruptiveness, academic performance, family adversity, parental support and unpopularity/ friendlessness. Its addition, however, caused the effect of parental supervision to become non-significant; the effect went from -0.12 to -0.04 after the predictor variable of deviant/dropout friends was added to the equation. Interaction terms between unpopularity/friendlessness, on one hand, and disruptiveness, academic performance and deviant/dropout friends, on the other hand, were also added to the equation but none were significant. We also tested interactions between deviant/ dropout friends, on one hand, and family adversity, academic performance parental supervision and parental support, on the other hand, but found none to be significant.

\section{Discussion}

The objective of the present study was to examine whether peer-related variables played a mediating, a moderating, a redundant or an additive role in the trajectory leading to early or late school dropout after controlling for early disruptiveness, academic problems and socio-familial variables. However, before addressing this issue specifically, it is worth examining the results pertaining to socio-familial, parental practices and personal dispositions.

Results showed that socio-family adversity has a direct link to school dropout. This finding is in line with data from Ensminger \& Slusarcick (1992), except that these authors also found that poverty and mother's level of education interacted with the child's 


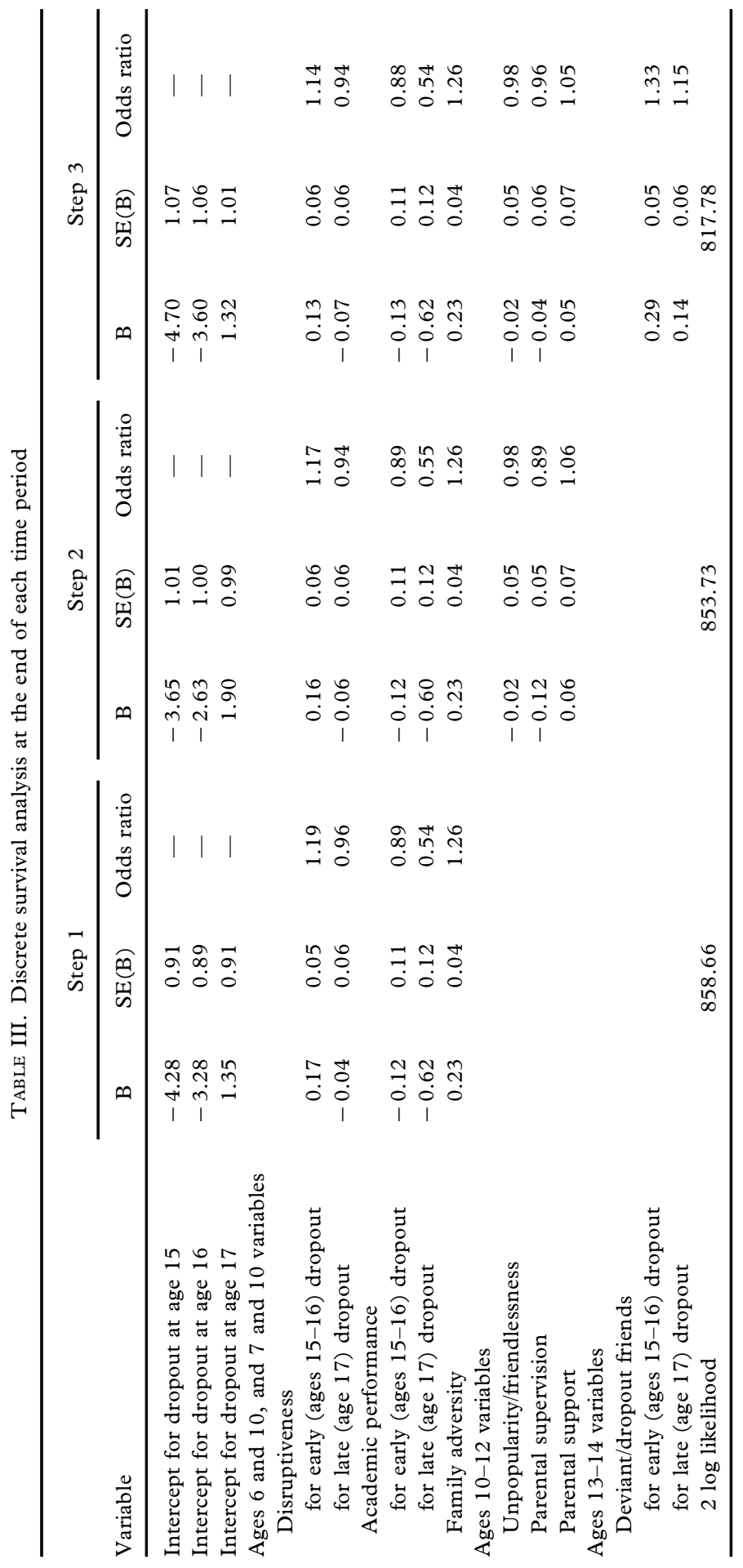


characteristics to predict school dropout. Differences in sample composition (i.e. low SES participants in the present sample) can help explain these differences.

Even after controlling for socio-family adversity, disruptiveness and academic performance both contributed significantly in predicting later dropping out of school. This finding supports earlier reports concerning the predictiveness of aggressive behaviours. The present study goes one step further, however, by showing that disruptiveness can be predictive even when assessed during the early school years. With the exception of Ensminger et al. (Ensminger \& Slusarcick, 1992; Ensminger et al. 1996) who assessed aggressive behaviour in grade one, all other studies have looked at aggressive behaviour during early adolescence (Cairns et al., 1989; Rumberger, 1995). However, disruptiveness in the present study only predicted early school withdrawal. Conversely, early academic performance predicted early and late dropout, although more strongly late withdrawal. If one considers that disruptiveness is indicative of a difficulty adjusting to social norms, then early dropping out of school seems to be influenced by this propensity to norm-breaking, rather than by learning difficulties. In turn, learning difficulties may discourage some children from graduating despite a socially normative profile. These suggestions are in line with a typology of school dropouts proposed by Janosz et al. (2000).

The non contribution of parent-related variables as main effects or moderators (when other predictors are taken into account) deserves a tentative explanation since they contradict previous findings (Howell \& Frese, 1982; Rumberger et al., 1990; Ensminger \& Slusarcick, 1992; Rumberger, 1995). Given the homogeneity of the present sample with respect to ethnicity, socio-economic variables and, possibly, educative practices, it is possible that parental support and parental supervision resulted in a restricted range of values. This has been confirmed by comparing the distribution from the present sample to the distribution of a nationwide representative sample in the Province of Quebec. It is also possible that the measure itself is biased because it originates from children's self-reports. These interpretations, however, must be challenged since, individually, parental support and parental supervision were significant predictors. Hence, their non contribution in the final model might have been due to the control of some other (related) variables not controlled in previous studies.

Negative social experiences (i.e. unpopularity/friendlessness) in the final model did not predict school dropout, once personal dispositions and family-related variables were controlled for. This finding contradicts speculations by Hymel et al. (1996) that peer-related variables would contribute unique variance in the prediction of school dropout. It also contradicts the contention by Parker \& Asher (1987) that the reasons for average or above intelligence dropouts lie more in social than in cognitive or parental factors. Present results suggest that not having friends in the classroom and being unpopular with classmates are markers of underlying personal and school problems and do not contribute to the pathway leading to dropping out of school. It must be acknowledged, however, that the present unpopularity/friendlessness measure differed from the more traditional peer rejection measure that has been linked in some, but not all, studies to school dropout. It may be that the present measure did not capture as much of the 'negative social experiences' as peer rejection. However, in line with suggestions from Hymel et al. (1996), the present measure tried to capture in one composite score two different elements which have been linked separately to school dropout: unpopularity and friendlessness (or social isolation). Moreover, some studies found no significant differences in later dropout rates as a function of sociometric status (including a group of rejected children; Kupersmidt \& Coie, 1990). The modest effect 
size $(r=0.19)$ reported by Comfort \& Kisher (1994) after a meta-analysis of seven studies that examined the links between different peer status measures (i.e. unpopularity, low acceptance, rejection) and later school dropout concur to the overall impression that unpopularity is not a clear predictor of school dropout. The effect sizes in most of the individual studies might have been even lower had the authors controlled for behavioral and/or academic difficulties, as in the present study. Finally, present results are concordant with findings by Cairns et al. (1989) who also failed to demonstrate a relation between social status (i.e. teacher rated popularity and peer rated social isolation in grade 7) and later withdrawal from school.

Association with deviant friends by early adolescence made an additive contribution to the process of school disengagement, above and beyond disruptiveness, school difficulties, parental practices and unpopularity/friendlessness. As suggested in the Introduction, such a contribution might operate through direct modeling effects (i.e. some deviant friends are dropouts) or through the increased involvement in drugs or delinquent behaviour incompatible with schoolwork. Present findings support Sutherland \& Cressey's (1980) view that students who associate with non school-orientated friends are more likely to develop attitudes not favourable to school achievement. In summary, association with deviant/dropout friends acts as a proximal precipitating factor on the decision to drop out from school.

Surprisingly, no interaction terms were found. For example, unpopularity/friendlessness or affiliation with deviant/dropout friends did not modify the risk of dropping out of school for boys who manifested disruptive behaviour or experienced academic difficulties. It is clear from the present findings that dropping out of school can be predicted by early behavioral dispositions and academic performance and that some social processes (i.e. association with deviant peers) contribute to this process. This advocates in favour of early preventive intervention aimed at reducing disruptive behaviour and academic difficulties with the distal objective of preventive school dropout. Association with conventional children should also be targeted by these prevention programs. As shown by Berndt \& Keefe (1995), conventional children may influence positively school performance and pro-school attitudes.

The present study is not without limitations, such as loss of participants through attrition, the assessment of males only, and use of an unpopularity/friendlessness measure which differed from the more traditional peer rejection measure. It also has some assets: large sample, longitudinal design, use of different sources to assess different variables thus avoiding capitalizing on shared method variance, and distinction between early and late dropouts. Future studies should try to overcome present limitations and extend the age at which dropout occurs to refine the contribution of the possible predictors. However, future studies should consider predictors from all possible sources, including peer-related variables. They should also consider the age at which dropping out of school occurs.

\section{Acknowledgements}

This research was made possible by grants from the Social Sciences and Humanities Research Council of Canada, the Conseil québécois de la recherche sociale and the National Health Research and Development Program. We wish to thank the authorities and directors of schools at the Montreal Catholic School Board as well as the teachers, children and parents for their first-rate collaboration. Lyse Desmarais-Gervais and Maria Rosa deserve our thanks for their participation in the collection or analysis of the data. 
Correspondence: F. Vitaro, Research Unit on Children's Psycho-social Maladjustment, University of Montreal, 3050 Edouard-Montpetit Blvd, Montreal (Quebec), Canada HST $1 \mathrm{~J} 7$.

\section{REFERENCES}

Berndt, T.J., \& Keefe, K. (1995). Friends' influence on adolescents' adjustment to school. Child Development, 66, 1312-1329.

Blishen, B.R., Carroll, W.K., \& Moore, C. (1987). The 1981 socioeconomic index for occupations in Canada. Canadian Review of Sociology and Anthropology, 24, 465-488.

Cairns, R.B., Cairns, B.D., \& Neckerman, H.J. (1989). Early school dropout: configurations and determinants. Child Development, 60, 1437-1452.

Coie, J.D. (1990). Toward a theory of peer rejection. In: S. R. Asher \& J. D. Coie (Eds) Peer rejection in childhood, pp. 365-402. New York: Cambridge University Press.

Comfort, C., \& Kisher, N. (1994). Relations of self-esteem, alienation and popularity to school dropout: A meta-analysis, Paper presented at the Annual Meeting of the Canadian Society for the Study of Education. Calgary, Canada, June.

Elliott, D.S., \& Voss, H.L. (1974). Delinquency and dropout. Lexington, MA: Lexington Books.

Ensminger, M.E., Lamkin, R.P., \& Jacobson, N. (1996). School leaving: A longitudinal perspective including neighborhood effects. Child Development, 67, 2400-2416.

Ensminger, M.E., \& Slusarcick, A.L. (1992). Paths to high school graduation or dropout: a longitudinal study of a first-grade cohort. Sociology of Education, 65, 95-113.

Garnier, H.E., Stein, J.A., \& Jacobs, J.K. (1997). The process of dropping out of high school: a 19-year perspective. American Educational Research fournal, 34, 395-419.

Howell, F.M., \& Frese, W. (1982). Early transition to adult roles: some antecedents and outcomes. American Educational Research fournal, 19, 51-73.

Huesmann, L.R., Eron, L.D., Lefkowitz, M.M., \& Walder, L.O. (1984). The stability of aggression over time and generations. Developmental Psychology, 20, 1120-1134.

Hymel, S., Comfort, C., Schonert-Reichl, K., \& McDougall, P. (1996) Academic failure and school dropout: The influence of peers. In: J. Juvonen \& K. R. Wentzel (Eds) Social Motivation: Understanding children's school adjustment, pp. 313-345. Cambridge: Cambridge University Press.

Janosz, M., LeBlanc, M., Boulerice, B., \& Tremblay, R.E. (2000). Predicting different types of school dropouts: A typological approach on two longitudinal samples. Fournal of Educational Psychology, 92, 171-190.

Kaplan, D.S., Peck, B.M., \& Kaplan, H.B. (1997). Decomposing the academic failure-dropout relationship: A longitudinal analysis. Fournal of Educational Research, 90, 331-343.

Kupersmidt, J.B. (1983). Predicting Delinquency and Academic Problems from Childhood peer status, paper presented at the Biennial Meetings of the Society for Research in Child Development, Detroit, April.

Kupersmidt, J.B., \& Coie, J.D. (1990). Preadolescent peer status, aggression, and school adjustment as predictors of externalizing problems in adolescence. Child Development, 61, 1350-1362.

Kupersmidt, J.B., Coie, J.D., \& Dodge, K.A. (1990). The role of poor peer relationships in the development of disorder. In: S. R. Asher \& J. D. Coie (Eds) Peer rejection in childhood, pp. 274-305. New York: Cambridge University Press.

Lorge, I., \& Thorndike, R.A. (1950). The Lorge-Thorndike Intelligence Tests. New York: Houghton Mifflin.

McMillen, M.M., Kaufman, P., Hausken, E.G., \& Bradby, D. (1993). Dropout rates in the United States: 1992. Washington, DC: U.S. Government Printing Office.

Ollendick, T.H., Weist, M.D., Borden, M.C., \& Greene, R.W. (1992). Sociometric status and academic, behavioral, and psychological adjustment: a five-year longitudinal study. fournal of Consulting and Clinical Psychology, 60, 80-87.

Parker, J.G., \& Asher, S.R. (1987). Peer relations and later personal adjustment: are low-accepted children at risk? Psychological Bulletin, 102, 357-389.

Pekarik, E.G., Prinz, R.J., Liebert, D.E., Weintraub, S., \& Neale, J.M. (1976). The Pupil Evaluation Inventory: a sociometric technique for assessing children's social behavior. Fournal of Abnormal Child Psychology, 4, 83-97.

Pirog, M.A., \& Magee, C. (1997). High school completion: the influence of schools, families, and adolescent parenting. Social Science Quarterly, 78, 710-724. 
Robins, L.N. (1978). Study childhood predictors of adult antisocial behavior: Replications from longitudinal studies. Psychological Medicine, 8(4), 611-622.

Rumberger, R.W. (1987). High school dropouts: a review of issues and evidence. Review of Educational Research, 57, 101-121.

Rumberger, R.W. (1995). Dropping out of middle school: a multilevel analysis of students and schools. American Educational Research fournal, 32, 583-625.

Rumberger, R.W., Ghatak, R., Poulos, G., Ritter, P.L., \& Dornbusch, S.M. (1990). Family influences on dropout behavior in one California high school. Sociology of Education, 63, 283-299.

Singer, J.D., \& Willett, J.B. (1993). It's about time: using discrete-time survival analysis to study duration and the timing of events. Fournal of Educational Statistics, 18, 155-195.

Statistics Canada (1995). Canadian Census. Government of Canada, Ottawa.

Steinberg, L., Dornbusch, S., \& Brown, B. (1992). Ethnic differences in adolescent achievement: an ecological perspective. American Psychologist, 47, 723-729.

Sutherland, E.H., \& Cressey, D.R. (1980). The theory of differential association: the problem for criminological theory. In: S. H. Traub \& C. B. Little (Eds) Theories of deviance, pp. 176-182. Itasca: F.E. Peacock Publisher.

Tremblay, R.E., Loeber, R., Gagnon, C., Charlebois, P., Larivée, S., \& LeBlanc, M. (1991). Disruptive boys with stable and unstable high fighting behavior patterns during junior elementary school. Fournal of Abnormal Child Psychology, 19, 285-300.

Velez, C.N., Johnson, J., \& Cowen, P. (1989). A longitudinal analysis of selected risk factors for childhood psychopathology. Fournal of the American Academy of Child and Adolescent Psychiatry, 28, 861-864.

Veroff, J., McClelland, L., \& Marquis, K. (1971). Measuring intelligence and achievement motivation in surveys. Final report to the U.S. Department of Health, Education and Welfare, Washington, D.C. 